\title{
El desarrollo en el Trabajo Social de Colombia: un campo transversal, disperso y polivalente
}

\author{
Maira Judith Contreras-Santos \\ Doctora en Urbanismo. Trabajadora social \\ Universidad Nacional de Colombia. Bogotá, Colombia \\ https:/ /orcid.org/0000-0002-0212-3886・mjcontrerass@unal.edu.co
}

Resumen

En Colombia, los paralelismos del Trabajo Social con el desarrollo, desde sus inicios hasta hoy, son esenciales. Sin embargo, las pesquisas sobre sus acervos son limitadas. En este artículo se expone una síntesis de la investigación documental realizada para visibilizar los rasgos del desarrollo impresos por colegas, desde 1987, en la Revista Colombiana de Trabajo Social del Consejo Nacional para la Educación en Trabajo Social (CONETS). Por lo tanto, se interpretan, de modo críticopropositivo, conocimientos, actitudes, prácticas y perspectivas de nuestra (in)disciplina-profesión sobre aquel dominio en dicho canal de divulgación (inter)nacional.

Palabras clave: Desarrollo; Revista Colombiana de Trabajo Social; CONETS; Redes.

Recibido: 07/01/2021 |Aprobado: 27/04/2021 | Publicado: 01/07/2021

(c) (1) (2) Esta obra está bajo una Licencia Creative Commons Atribución-NoComercialCompartirIgual 4.0 Internacional.

Financiación o proveniencia del artículo: Los contenidos expuestos en este artículo son componentes de la investigación "El desarrollo en el Trabajo Social colombiano" que adelanta su autora en la Universidad Nacional de Colombia.

¿Cómo citar este artículo? / How to quote this article?

Contreras-Santos, M. J. (2021). El desarrollo en el Trabajo Social de Colombia: un campo transversal, disperso y polivalente. Prospectiva. Revista de Trabajo Social e intervención social, (32), 173-200. doi: 10.25100/prts.v0i32.10910. 
Contreras-Santos

\title{
The development in Colombian Social Work: a transversal, dispersed and multipurpose field
}

\begin{abstract}
In Colombia, the links between social work and the development, from its origins to date, are essential. However, the research on the matter is limited. This article presents a synthesis of the documentary research about features of development carried out by colleagues since 1987, and printed in the Colombian Journal of Social Work of the National Council for Education in Social Work (CONETS). Therefore, the article interprets, in a critical-propositional mode, knowledge, attitudes, practices and perspectives of our (in)discipline-profession in the said (inter)national divulgation channel.

Keywords: Development; Colombian Journal of Social Work; CONETS; Networks.

Sumario: 1. Introducción, 2. Metodología, 3. Hallazgos, 3.1. Los conocimientos sobre el desarrollo en el Trabajo Social, 3.2. Las actitudes en el Trabajo Social ante el desarrollo, 3.3. Las prácticas del desarrollo en el Trabajo Social, 3.4. Las perspectivas del Trabajo Social en cuanto al desarrollo, 4. Conclusiones, 5. Agradecimientos, 6. Referencias bibliográficas.
\end{abstract}


Contreras-Santos

\section{Introducción}

En Colombia, los vínculos instaurados por el Trabajo Social con el desarrollo, desde sus orígenes hasta la fecha, son vitales. En realidad, los ciclos de conocimientos alusivos a esos nexos son progresivos a partir de la segunda mitad del siglo $\mathrm{XX}$, pero sus diásporas son vastas $\mathrm{y}$, simultáneamente, sus investigaciones en torno a las constelaciones son exiguas. En consecuencia, es clave potenciar los procesos de recolección, procesamiento, análisis e interpretación crítico-propositiva de dichos ensambles. Para lograr este propósito, es fundamental acudir a sus fuentes primarias, secundarias y terciarias.

Conscientes de la magnitud de la tarea, es imprescindible desplegar estudios que incorporen (de-re) construcciones de nuestras memorias colectivas en lo que respecta a los horizontes, los referentes y los elementos de esta unidad de análisis en decursos introspectivos que nos permitan aprender para, mínimamente, reducir los riesgos de "repetir la historia".

Con el interés de contribuir a los quehaceres previstos, en los dos apartados de este artículo se visibilizan las imbricaciones del Trabajo Social con el desarrollo descubiertas por colegas en los ejemplares de la Revista Colombiana de Trabajo Social del Consejo Nacional para la Educación en Trabajo Social (CONETS).

\section{Metodología}

La cronografía del Trabajo Social muestra que esta (in)disciplina-profesión surge y evoluciona con la impronta del desarrollo moderno. Como es sabido, a finales del siglo XIX, en la universidad europea germina el Trabajo Social para formar profesionales mediadores entre el progreso burgués y el retroceso obrero que contribuyan a resolver las exclusiones de la expansión capitalista, puesta en marcha seis siglos antes por los gremios medievales. Dicho ascendiente causal se sitúa en América. En 1905, Mary Richmond funda la primera escuela norteamericana de Trabajo Social en Estados Unidos y en 1925 Alejandro del Río organiza la primera escuela latinoamericana de Trabajo Social en Chile. En lo sucesivo, la tendencia precursora se extiende por el resto de los países del continente. Verbigracia, en 1936, María Carulla estructura la primera escuela de Trabajo Social en Colombia para atenuar las secuelas político-laborales del despliegue capitalista promovido a nivel nacional con apoyo estadounidense (Contreras-Santos, 2006, 2010, 2017; Martínez, López, Saboyá, Rojas y Poveda, 1981; Santos de Santos, 2016). 
Contreras-Santos

A partir de entonces, hasta 2021, en Colombia han sido creadas escuelas de Trabajo Social en universidades públicas y privadas de ciudades mayores, maduras, adultas, grandes y jóvenes, adolescentes y embrionarias ${ }^{1}$, con singulares programas curriculares, en las cuales, de maneras tácitas y expresas, las actividades de docencia, investigación y extensión son impregnadas por el desarrollo moderno. Este último, más que un tópico lejano y sustancial de ciertos campos científicos, es un eje transversal en nuestra (in)disciplina-profesión, y sus estudios deberían componer un imperativo en el universo de las escuelas de Trabajo Social que facilite desentrañar sus resultados, efectos e impactos en la sociedad, así como en la naturaleza.

Ahora bien, cada escuela de Trabajo Social presenta un devenir exclusivo. Sin embargo, desde sus bosquejos, con distintos propósitos, todas han sido proclives a (re)constituir su propia comunidad académica. Las huellas de su intencionalidad perduran en incontables fuentes orales y escritas de las mencionadas unidades docentes.

Para ilustrar esto, basta decir que Mejía-Naranjo (2003), basado en Ángel (1976) y en sus trabajos, explica cómo, por iniciativa de las escuelas de asistencia social vinculadas a los colegios mayores², en 1951 se constituyó la Asociación Colombiana de Escuelas de Servicio Social con una dinámica reflexiva y analítica sobre la formación de las asistentes sociales que, a la luz del contexto nacional, convirtió una profesión de nivel intermedio y asistencial en una profesión de nivel universitario. Según Mejía-Naranjo (2003), la Asociación Colombiana de Escuelas de Servicio Social se transformó en el Consejo Nacional para la Educación en Trabajo Social (CONETS) en 1965, dado su propósito de contribuir a la definición de los requisitos para la formación profesional en Trabajo Social. Para Mejía-Naranjo, el nombre del CONETS reflejó la fuerte influencia que recibió esta corporación del Consejo Nacional para la Educación en Trabajo Social de los Estados Unidos (Mejía-Naranjo, 2003, 2014). Cincuenta y cinco años después, en Colombia, el Conets mantiene su liderazgo y su compromiso con la cualificación de la educación en Trabajo Social, ya que en su trayectoria implementa acciones situadas de información, formación, organización, participación y movilización con su comunidad (in)disciplinar-profesional (Consejo Nacional para la Educación en Trabajo Social [CONETS], 2020).

1 Clasificación del Departamento Nacional de Planeación (DNP), 2014.

2 Esto es, del Colegio Mayor del Rosario, Colegio Mayor de Cundinamarca, Colegio Mayor de Bolívar y de la Escuela de Servicio Social de Medellín. Posteriormente, se afiliaron la Escuela de Servicio Social de Cali y la Universidad Femenina de Santander. 
Contreras-Santos

Entre las acciones referidas se encuentran sus estímulos a la producción, circulación y aplicación de conocimientos en Trabajo Social sin olvidar sus dimensiones epistemológicas, ético-políticas, ontológicas, teóricas, metodológicas e instrumentales. Cada fase de tales ciclos de conocimientos evidencia un concepto y unas tareas específicas. Por ejemplo, con base en la revisión de variadas fuentes, es sencillo inferir que el CONETS, a partir de su constitución, asume la emisión de conocimientos en Trabajo Social como una obra libre, colaborativa e incluyente que comprende desde las difusiones hasta las (re)problematizaciones de temas de nuestra (in)disciplina-profesión a escalas (inter)nacional, regional, departamental, municipal y local en múltiples eventos de docencia, investigación y extensión (intercambios, capacitaciones, asambleas, congresos, seminarios, encuentros, foros, mesas redondas, etcétera).

Sin embargo, las memorias físicas y virtuales de los conocimientos irradiados por el CONETS tienden a ser inaccesibles, debido a que los lugares físicos en los cuales se almacenan no son abiertos. Para ilustrar basta con rememorar, durante los últimos años, las imposibilidades de acceder a las memorias de los congresos nacionales de Trabajo Social archivadas en el Consejo Nacional de Trabajo Social. Asimismo, estas memorias no se digitalizan y, por ende, no se ubican en sitios virtuales. De ahí que en el Trabajo Social se desaprovechen valiosas oportunidades de generar nuevos conocimientos estimando los conocimientos expuestos en esos congresos. Para cambiar este derrotero es primordial desplegar ejercicios descriptivos, analíticos, interpretativos y propositivos que, al menos, compatibilicen tareas de ubicación, restitución, compilación, revisión, clasificación, catalogación, categorización y estructuración de aquellos conocimientos.

En todo caso, el CONETS, desde sus comienzos, utiliza medios orales y escritos para incentivar la producción intelectual docente en el Trabajo Social; tanto que, en 1996, se inscribió como editorial en la Cámara Colombiana del Libro (Mejía-Naranjo, 2003, pp. 24-26). Entre sus publicaciones se cuentan textos derivados de investigaciones, libros homenajes, colecciones, material pedagógico y revistas. El medio escrito de mayor periodicidad concebido por el CONETS para divulgar esa creación continúa siendo la Revista Colombiana de Trabajo Social (en adelante, Revista).

Por consiguiente y ponderando la unidad de análisis de este trabajo, la pregunta central es: ¿cuáles son los rasgos del desarrollo manifiestos en la Revista? Esta se divide en tres interrogantes: ¿cuál es la trayectoria de la Revista? ¿Cuáles son los conocimientos, las actitudes y las prácticas del Trabajo Social sobre el desarrollo? ¿Cuáles son las perspectivas del Trabajo Social ante el desarrollo? 
Contreras-Santos

Para responder estas cuestiones se gestó un método con fases y actividades probadas de la investigación documental. Estas fueron: (i) recolección de información en fuentes primarias, especialmente de Jesús Glay Mejía Naranjo (presidente del CONETS de 1986 a 1998 y cocreador de la Revista), Rafael Alberto Zambrano (actual integrante del comité editorial de la Revista) y Zulma Cristina Santos Kerguelén (lectora asidua de la Revista); (ii) revisión de fuentes secundarias y terciarias acerca del desarrollo en el Trabajo Social; (iii) exploración de la Revista (ubicación y reconocimiento de su umbral y su desenvolvimiento); (iv) procesamiento de los artículos en cuyos títulos aparece el término desarrollo (ubicación, revisión, organización, clasificación, codificación y concatenación en el programa Nvivo 12); y (v) descripción, análisis e interpretación crítico-propositiva de esos contenidos.

\section{Hallazgos}

El CONETS es el organismo representativo del 67\% (24 de 36) de las unidades académicas de Trabajo Social que funcionan con las normas vigentes de la educación superior universitaria en Colombia (CONETS, 2020). A partir de 1965, se (re)constituye para cristalizar su misión:

El Consejo Nacional para la Educación en Trabajo Social -CONETS- es una organización de derecho privado y carácter académico, constituida por las Unidades Docentes de Trabajo Social de Colombia, comprometida con el mejoramiento de la calidad de la educación en Trabajo Social, con el propósito de lograr la formación de Trabajadores Sociales con un excelente desempeño profesional, alto nivel académico, motivados al logro del desarrollo humano integral y capaces de liderar procesos de cambio.

Para, [sic] lograr sus propósitos realiza, fomenta y estimula acciones de carácter académico, investigativo, de capacitación, de coordinación e información, que conduzcan al mejoramiento de la calidad de la educación en Trabajo Social y fortalezcan las Universidades afiliadas. (CONETS, 2020)

Esa misión conlleva información para alcanzar sus propósitos. En esta acción se ubica la elaboración y la extensión de la Revista, que nace gracias al esfuerzo conjunto del CONETS, la Federación Colombiana de Trabajadores Sociales (FECTS) y el Consejo Nacional de Trabajo Social, 51 años después del surgimiento del Trabajo Social en el país (1987).

La Revista, con sede inicial en la Universidad del Valle, se asume en sus editoriales como canal, contribución, espacio, esfuerzo, estrategia, experiencia, instrumento, 
Contreras-Santos

invitación, medio, así como proyecto académico, concertado, amplio, general y especializado para, en síntesis:

- Contribuir al cumplimiento de los objetivos del CONETS.

- Visibilizar las tareas de las unidades académicas integrantes del CONETS.

- Impulsar la incubación, la difusión y la apropiación de conocimientos del Trabajo Social, los organismos de Trabajo Social y las disciplinas de las Ciencias Humanas.

- Recopilar la fecundación de ideas, temas, problemas, investigaciones y experiencias de trabajadores sociales y profesionales de las Ciencias Humanas manifiestas en los complejos contextos latinoamericanos y, especialmente, colombianos.

- Difundir esta fertilización como aporte a la consolidación de la comunidad académica de Trabajo Social y de otras comunidades académicas con proyecciones (inter)nacionales.

- Propiciar análisis, diálogos, debates, críticas, reflexiones, socializaciones e intercambios de conocimientos especializados y situados en el Trabajo Social, los organismos de Trabajo Social y las disciplinas de las Ciencias Humanas. (Consejos Editoriales de la Revista, N: 1-26)

En su devenir la Revista ha experimentado: (i) modificaciones de diseño, diagramación y política editorial; (ii) limitaciones en costos, mercadeos y recepción de artículos; (iii) desafíos con respecto a cumplimientos de los requisitos de indexación impuestos por Colciencias, opacidades alusivas a las primacías de las publicaciones científicas indexadas y respuestas frente a los retos sociales; (iv) autoevaluaciones - en línea con la visión, la misión y los objetivos del CONETS - para su reorientación, colaboración de unidades docentes y reposicionamiento (Consejos Editoriales de la Revista, N: 1-26). Además, la Revista ha dedicado sus números a pertinentes, relevantes y significativos temas del Trabajo Social (Tabla 1). 
Contreras-Santos

Tabla 1. Temas centrales de la Revista.

\begin{tabular}{|c|c|c|c|}
\hline Año & N. Revista & Tema & Tema central \\
\hline 1988 & 2 & \multirow{6}{*}{$\begin{array}{l}\text { Generales } \\
\quad(6)\end{array}$} & Democracia y participación social. \\
\hline 1989 & 3 & & $\begin{array}{l}\text { Laboral, metodología, participación comunitaria y seguridad } \\
\text { social. }\end{array}$ \\
\hline 1994 & 7 & & Visión y prospectiva del desarrollo social. \\
\hline 1996 & 9 & & Familia, gerencia social, seguridad social y ecología. \\
\hline 2000 & 14 & & Política social, calidad de vida y construcción de la paz. \\
\hline 2019 & 26 & & Contextos de paz. \\
\hline 1998 & 12 & \multirow{6}{*}{$\begin{array}{l}\text { Particulares } \\
\qquad(6)\end{array}$} & $\begin{array}{l}\text { Mirada prospectiva de construcción de los escenarios } \\
\text { futuros de la profesión, formación profesional, medio } \\
\text { ambiente y familia. }\end{array}$ \\
\hline 2001 & 15 & & Políticas sociales, familia y Trabajo Social. \\
\hline 2004 & 18 & & $\begin{array}{c}\text { Debates en torno a la cuestión social y desafíos para la } \\
\text { profesión en los países iberoamericanos. }\end{array}$ \\
\hline 2005 & 19 & & $\begin{array}{c}\text { Lo social en América Latina. Debates sobre lo profesional. } \\
\text { Reflexiones en torno a la familia. }\end{array}$ \\
\hline 2006 & 20 & & $\begin{array}{c}\text { Trabajo Social e Intervención. Reflexiones sobre el sujeto. } \\
\text { Estudios de género. }\end{array}$ \\
\hline 2011 & 23 & & $\begin{array}{c}\text { Reflexión y debate de problemas asociados a la política } \\
\text { pública y la intervención profesional en contextos } \\
\text { particulares. }\end{array}$ \\
\hline 1987 & 1 & \multirow{13}{*}{$\begin{array}{l}\text { Singulares } \\
\quad(13)\end{array}$} & $\begin{array}{c}\text { Foro Nacional "Situación actual y perspectivas de la práctica } \\
\text { del Trabajo Social en Colombia". }\end{array}$ \\
\hline 1991 & 4 & & Situación actual y perspectivas de acción profesional. \\
\hline 1992 & 5 & & $\begin{array}{c}\text { Asamblea de la Asociación Latinoamericana de Escuelas de } \\
\text { Trabajo Social (Alaets). }\end{array}$ \\
\hline 1993 & 6 & & Congresos Mundiales de Trabajo Social. \\
\hline 1995 & 8 & & Alaets: un compromiso latinoamericano. \\
\hline 1997 & $10-11$ & & Congreso Mundial de Trabajo Social. \\
\hline 1999 & 13 & & $\begin{array}{c}\text { XVI Congreso Latinoamericano de Escuelas de Trabajo } \\
\text { Social. Seminario Internacional sobre Calidad de la } \\
\text { Educación en Trabajo Social (1998). }\end{array}$ \\
\hline 2002 & 16 & & Trabajo Social de cara al país. \\
\hline 2003 & 17 & & XI Congreso Colombiano de Trabajo Social. \\
\hline 2008 & 21 & & $\begin{array}{c}\text { Lectura crítica sobre el desarrollo y reflexión en la formación } \\
\text { y quehacer del Trabajo Social. }\end{array}$ \\
\hline 2009 & 22 & & Debate y reflexión sobre los desarrollos del Trabajo Social. \\
\hline 2013 & 24 & & $\begin{array}{l}\text { Apuestas reflexivas sobre la acción, la formación y el } \\
\text { contenido disciplinar del Trabajo Social. }\end{array}$ \\
\hline 2016 & 25 & & XIV Congreso Colombiano de Trabajo Social. \\
\hline
\end{tabular}

Fuente: elaboración propia. 
Contreras-Santos

Como se observa, correspondiente con sus objetivos, el CONETS ha estimulado la divulgación de materias generales, particulares y singulares del Trabajo Social, considerando diversas corrientes epistemológicas, ético-políticas, ontológicas, contextuales, teóricas y metodológicas.

En cada ejemplar de la Revista, los temas se describen, analizan, interpretan y desagregan en subtemas. Uno de ellos se refiere al desarrollo en el Trabajo Social, el cual se adopta como unidad de análisis de la presente investigación. Para contribuir a su comprensión, es necesario identificar sus rasgos en este nicho. Enseguida, se procede con un corpus documental compuesto por el total de artículos de la Revista en cuyo título se inserta el término "desarrollo", esto es 12 textos (Tabla 2).

Tabla 2. Artículos de la Revista con el término "desarrollo" incluido en sus títulos.

\begin{tabular}{|c|c|c|c|}
\hline Año & $\begin{array}{c}\text { N. } \\
\text { Revista }\end{array}$ & Título del artículo & Autoras-es \\
\hline 1992 & 5 & $\begin{array}{c}\text { La planeación estratégica y el desarrollo de } \\
\text { personal de las empresas }\end{array}$ & Bernardo Gaitán-Quijano (1992) \\
\hline 1994 & 7 & $\begin{array}{l}\text { Relatoría del Seminario Latinoamericano y } \\
\text { Caribeño "Pobreza y Desarrollo" }\end{array}$ & Seno Antonio Cornely (1994) \\
\hline 1995 & 8 & $\begin{array}{l}\text { Visión y prospectiva del desarrollo social a } \\
\text { escala mundial }\end{array}$ & $\begin{array}{c}\text { Antonio Jaime Elizalde-Hevia } \\
\text { (1995) }\end{array}$ \\
\hline 1998 & 12 & $\begin{array}{c}\text { Desarrollo humano en la organización -Una } \\
\text { visión sistémica- }\end{array}$ & $\begin{array}{c}\text { Carlos Eduardo Torres-Sánchez } \\
\text { (1998) }\end{array}$ \\
\hline 1999 & 13 & $\begin{array}{l}\text { Trabajo Social, identidad y desarrollo } \\
\text { La formación académica del Trabajador } \\
\text { Social Colombiano. Su papel en la } \\
\text { transformación y desarrollo del país }\end{array}$ & $\begin{array}{c}\text { Cecilia Inés López-Jiménez (1999) } \\
\text { Rosa Margarita Vargas de Roa } \\
(1999)\end{array}$ \\
\hline 2000 & 14 & $\begin{array}{c}\text { Colombia al comienzo del nuevo siglo: paz, } \\
\text { desarrollo y gobernabilidad }\end{array}$ & Alejo Vargas-Velásquez (2000) \\
\hline \multirow[t]{2}{*}{2009} & 21 & $\begin{array}{c}\text { Dinámicas sociales y gestión del desarrollo } \\
\text { Colombia: política social y participación en } \\
\text { los Planes Nacionales de Desarrollo 1998- } \\
2003\end{array}$ & $\begin{array}{l}\text { Ana Elizabete Mota (2009) } \\
\text { Ricardo Briceño-Ayala y Zilia } \\
\text { Daisy Ruiz-Guataquí (2009) }\end{array}$ \\
\hline & & $\begin{array}{c}\text { Educación para el desarrollo en procesos de } \\
\text { planeación participativa } \\
\text { La formación en Trabajo Social para el } \\
\text { desarrollo local y regional } \\
\text { Conclusiones del Congreso Nacional de } \\
\text { Trabajo Social 2007. “Desarrollo local y } \\
\text { regional, realidades y desafíos para el siglo } \\
\text { XXI” }\end{array}$ & $\begin{array}{l}\text { Esperanza Gómez-Hernández } \\
\text { (2009) } \\
\text { Rosa Margarita Vargas de Roa } \\
(2009) \\
\text { José Roberto Álvarez-Múnera } \\
\text { (2009) }\end{array}$ \\
\hline
\end{tabular}

Fuente: elaboración propia. 
Contreras-Santos

En este corpus documental, el término desarrollo se menciona 280 veces (Figura 1) y hace referencia a conocimientos, actitudes, prácticas y perspectivas del Trabajo Social relativas al desarrollo.

Figura 1. Enunciaciones del desarrollo en el corpus documental.

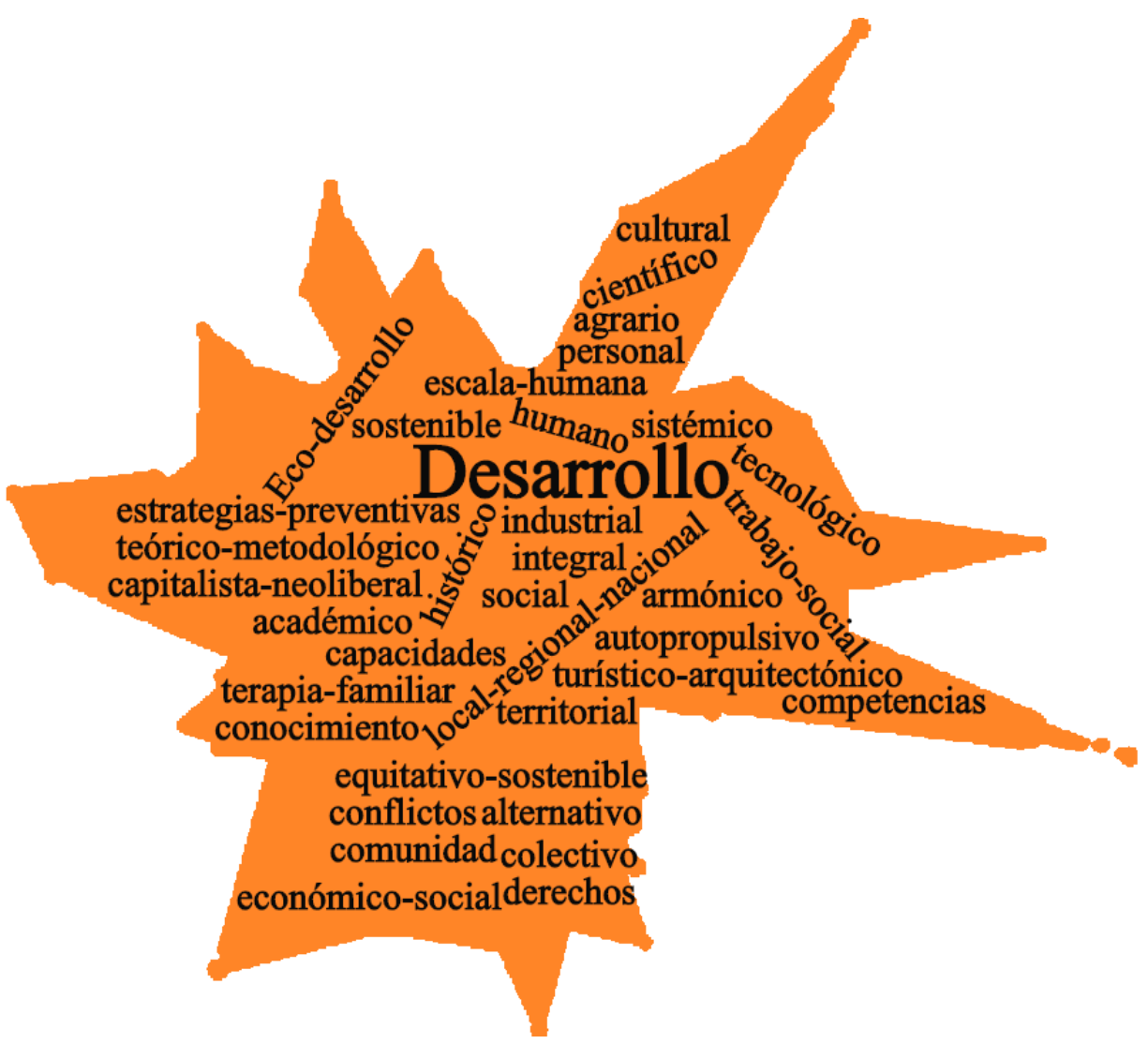

Fuente: elaboración propia.

\subsection{Los conocimientos sobre el desarrollo en el Trabajo Social}

En el corpus documental el término desarrollo se usa 80 veces con distintos significados, conceptos y atributos (Figura 2). 
Contreras-Santos

Figura 2. Conocimientos sobre el desarrollo en el Trabajo Social.

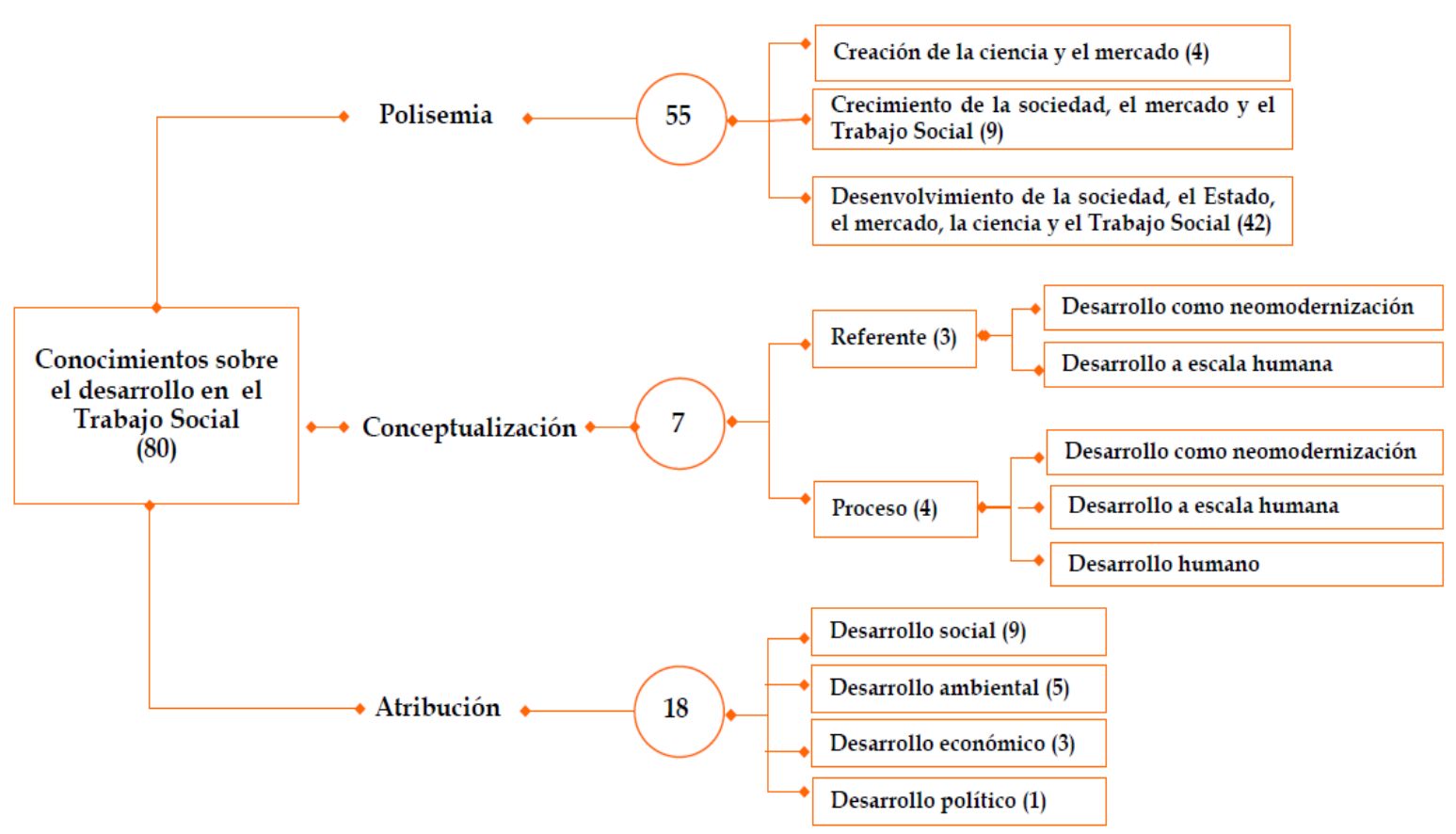

Fuente: elaboración propia.

En lo concerniente a la polisemia, el desarrollo se instala 55 veces con tres acepciones: (i) creación de la ciencia y del mercado (4); (ii) crecimiento de la sociedad, el mercado y el Trabajo Social (9); y (iii) desenvolvimiento de la sociedad, el Estado, el mercado, la ciencia y el Trabajo Social (42).

Esta disposición es similar a la localización habitual del desarrollo en la vida cotidiana, así como en los diferentes campos de la ciencia e, incluso, en su propia órbita. Las procedencias de esta polisemia son heterogéneas, más favorecen captar tránsitos de posiciones "inferiores a superiores", tanto como se plantea en la historiografía consuetudinaria de este término.

En lo concerniente a la conceptualización, el desarrollo se explica 7 veces como referente (3) y como proceso (4). En el primer caso, las definiciones del desarrollo expuestas se ajustan a los conceptos de desarrollo como: (i) neomodernización, porque impulsa a los países pobres por una vía que les induce a superar el "subdesarrollo"; y (ii) a escala humana, en virtud de que incorpora la noción de satisfactores de las necesidades fundamentales; promueve el ser antes que el tener; asume al ser humano como su centro, meta, razón de ser, actor y protagonista. 
Contreras-Santos

En el segundo caso, las definiciones del desarrollo expresadas se acoplan a los conceptos de desarrollo como: (i) neomodernización, dado que se le homologa con progreso, crecimiento, adelanto y desenvolvimiento; (ii) a escala humana, porque se compagina como proceso múltiple en sus dimensiones y polivalente en sus contenidos que logra los mayores niveles de sinergia entre las necesidades humanas y los requerimientos surgidos de la reproducción grupal y societal; y (iii) humano, ya que se asume como proceso continuo de crecimiento y cambio de las condiciones, capacidades y potencialidades del trabajador.

Los conocimientos del desarrollo visualizados ocupan lugares destacados en el discurso del desarrollo moderno que fue instalado en Latinoamérica tras la segunda postguerra mundial ${ }^{3}$. Esto en el Trabajo Social evidencia concurrencias de revisiones críticas al desarrollo, así como de adjetivaciones a los conceptos del desarrollo dirigidas, con o sin intenciones, a sus reforzamientos. Por ejemplo, el desarrollo a secas se afronta con desarrollo social o desarrollo humano integral. Mas, parecen olvidar la opción creciente del posdesarrollo tendiente a reemplazar al desarrollo mismo. Entonces, sin ningún interés de interpelar tan ostensible contradicción, es necesario aprovechar este vestigio para resaltar la oportunidad de fortalecer la investigación atinente a los conglomerados del desarrollo moderno inserto en el Trabajo Social.

En lo concerniente a la atribución, el desarrollo se describe 18 veces para establecer facciones sociales, ambientales, económicas, políticas y culturales con las cuales se le suele explicar, refrendar o impugnar en el mundo occidental.

En términos de desarrollo social (9), se afirma que debe contemplar: (i) la participación como medio, objetivo y producto de este; (ii) temas como la ternura, la cooperación, el diálogo, la apertura al otro, la solidaridad, la transparencia y la inocencia; (iii) las personas, no las cosas; (iv) las capacidades propias para encarar necesidades recurrentes en expansión; (v) las acciones económicas, políticas y culturales desplegadas en los más variados ámbitos de la vida humana; (vi) la "lógica popular"; (vii) los modos de pensar, sentir, relacionarse y hacer inherentes a la cultura de los "pobres"; (viii) las experiencias de la economía popular; (ix) los valores del ser y el conocer; y (x) la superación de la pobreza. En términos de desarrollo ambiental (5), se asevera que: (i) las inversiones inteligentes, la responsabilidad social de las empresas, la generación de empleos, el incremento de la renta de la población local, el aumento del recaudo de impuestos, la producción de riqueza y la protección de la biodiversidad son componentes del ciclo eficaz de desarrollo sostenible de la Conferencia de Río; (ii) los

3 Véase una caracterización de estos conceptos en Contreras-Santos (2017). 
Contreras-Santos

límites transgredidos originan situaciones catastróficas o desplomes de los sistemas en el desarrollo sustentable; (iii) la dimensión territorial de la pobreza urbana es esencial para el desarrollo social; (iv) son asunto de reflexión las implicaciones ambientales del desarrollo en todas las escalas; las iniciativas, las políticas y los programas ambientales; los efectos de los acuerdos internacionales en los territorios; las propuestas y los seguimientos a los planes de ordenamiento territorial; la relación entre economía, ecología, ambiente y paz; los reasentamientos humanos por efecto de los desastres naturales y afines; y (v) el crecimiento económico elevado, técnicamente sostenible y ambientalmente sustentable es parte de las nuevas tendencias de desarrollo. En términos de desarrollo económico (3), se precisa que: (i) el desarrollo económico y social se articulan; (ii) en el desarrollo humano, la pobreza, el desempleo y la desigualdad determinan los estados de precariedad de la población; y (iii) en el desarrollo humano, la responsabilidad social se orienta a la protección del individuo, creando bienes económicos según las necesidades y funciones del individuo. En términos de desarrollo político (1), se conjugan: participación, concertación, manejo de conflictos, planeación, administración efectiva e impacto positivo en las poblaciones a las cuales se dirige la acción en las nuevas organizaciones que deben ser escuelas de desarrollo humano.

Los atributos asignados al desarrollo son producidos, puestos en circulación y manejados en el dominio del desarrollo moderno, con referentes de orden semejante, es decir modernos. Quizás, por esta razón, aunque parecen contradictorios, son propensos a complementarse sin mayores problemas. Esta atribución constata la conceptualización expuesta porque se interpelan los componentes deficientes o carentes del desarrollo para reemplazarlos o introducir propiedades inéditas que favorezcan su fortalecimiento Presuntamente, el desarrollo en el Trabajo Social es una idea que todavía no es posible desechar por motivos complejos. Entre otros, porque en Colombia, a partir de 1991, el "desarrollo" guía las intervenciones públicas en las cuales se ubican las y los trabajadores sociales. Pese a ello o por ello, vale la pena decir que analizar las características de este asunto en las actividades de docencia, investigación y extensión del Trabajo Social, simultáneamente con sus (im)posibilidades de complemento, reforma o transformación seguirá siendo crucial en su devenir.

\subsection{Las actitudes en el Trabajo Social ante el desarrollo}

En el corpus documental existen 32 posturas sobre el desarrollo en sí, aunadas a los (des-re)encuentros de este con la sociedad, el Estado, el mercado y el Trabajo Social en las dimensiones ontológicas, contextuales, teóricas, metodológicas e instrumentales, como se puntualiza a continuación (Figura 3). 
Contreras-Santos

Figura 3. Las actitudes en el Trabajo Social ante el desarrollo.

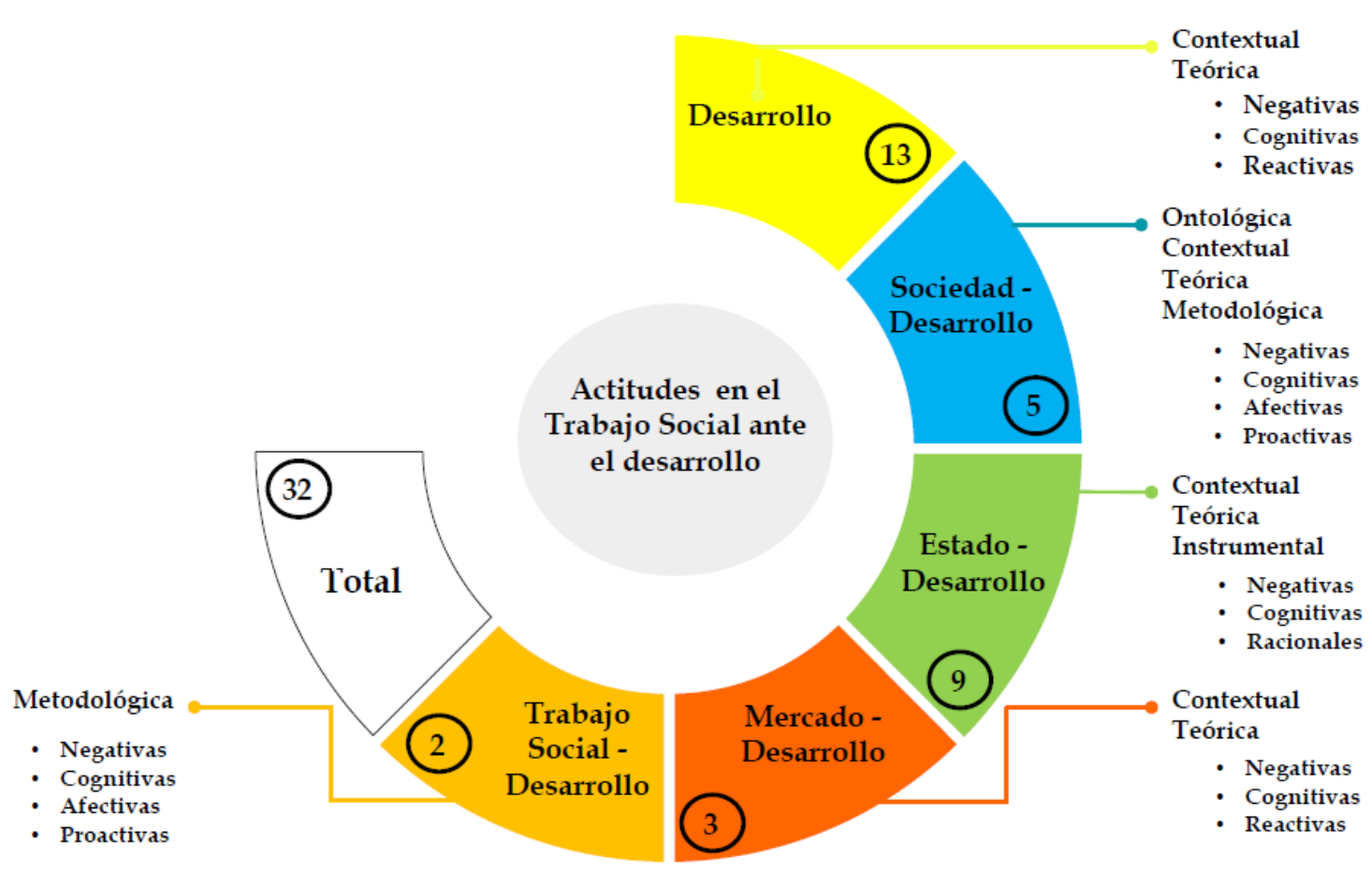

Fuente: elaboración propia.

Las posturas sobre el desarrollo en América Latina y Colombia son negativas, cognitivas y reactivas (13): (i) en la dimensión contextual, porque al desarrollo se le imputan las causas de la pobreza; los arrasamientos de los pueblos del Sur para impulsarlos a imitar a los países del Norte; el sobredimensionamiento de la racionalidad económica dominante; la obediencia a la lógica de la (re)producción de la burguesía financiera transnacional; su perverso reflejo en los cultivos ilícitos [sic]; su fracaso al enfrentar el hambre, la miseria, el analfabetismo, la violencia, la degradación moral o el agotamiento de los recursos naturales; su intrínseca desigualdad social; la presencia de desarrollo técnico y crecimiento económico acumulativo sin desarrollo social; los alejamientos de los capitales frente a cualquier zozobra política; y (ii) en la dimensión teórica, en la medida en que el desarrollo: de unos se hace a costa del empobrecimiento de otros; es idea eurocéntrica, forma de percepción moldeadora de la realidad, mito alienador de las sociedades, cuasi religión, fantasía desatadora de pasiones, ideologías y violencias con un sistema de lenguaje domesticador de las poblaciones de los países "más pobres"; nace y crece junto a la pobreza; se deforma como arma para erradicar la pobreza y la desigualdad. 
Contreras-Santos

Las posturas sobre las conexiones delineadas entre el desarrollo y la sociedad en el corpus documental son negativas, cognitivas, afectivas y proactivas (5): (i) en la dimensión ontológica, en razón a que el desarrollo excluye actores para eliminar diferencias políticas u oposiciones a sus propuestas; (ii) en la dimensión contextual, debido a que los modelos de desarrollo colombianos descartan grupos de los beneficios del mismo desarrollo; (iii) en la dimensión teórica, habida cuenta de que el neoliberalismo aumenta la desigualdad y hace inviable la conquista de la justicia social; al igual que son obstáculos para el desarrollo la pobreza y la desigualdad, la política social, la crisis de responsabilidad social, la violencia y la deshumanización del ser y de sus circunstancias de vida; (iv) en la dimensión metodológica, ya que el carácter residual de programas sociales compensatorios, la disminución del gasto y la cobertura, la focalización selectiva y la restricción de los servicios de bienestar social, junto a enfoques asistencialistas y privatización de los servicios sociales, son factores incidentes en el bajo impacto del desarrollo social del país.

Las posturas sobre las conexiones trazadas entre el Estado y el desarrollo en el corpus documental son negativas, cognitivas y racionales (9): (i) en la dimensión contextual, a medida que el Estado se transforma en promotor de la privatización bajo criterios de viabilidad financiera, reducción del déficit fiscal y, por consiguiente, del gasto público y de la inversión social, dada la instalación de los modelos de desarrollo imperantes de los organismos económicos internacionales; asume el rol de inductor del desarrollo económico, propiciando una base productiva integrada a las necesidades de los oligopolios internacionales y ocasionando endeudamiento externo para costear su expansión; carece de planteamientos acerca de reformas alusivas a la reinserción que varíen sustancialmente el estilo de desarrollo; su modernización, centralización y privatización sustituyen los fines de desarrollo por la obtención de indicadores de eficiencia y eficacia; (ii) en la dimensión teórica, a causa de que el desarrollo no está en manos del Estado; y, (iii) en la dimensión instrumental, porque los Gobiernos imponen sus intereses partidistas en los planes nacionales de desarrollo; y los procedimientos de participación en estos planes difícilmente fomentan la participación de la ciudadanía en la determinación de los derroteros que canalicen el accionar estatal en pro del desarrollo colectivo.

Las posturas sobre las conexiones perfiladas entre el desarrollo y el mercado son negativas, cognitivas y reactivas (3): (i) en la dimensión contextual, toda vez que la crisis mundial fue producida por el apoyo financiero promovido con fondos que no se dispusieron para proyectos de bienestar social y desarrollo económico afirmando que la globalización dificulta fortificar el desarrollo; (ii) en la dimensión teórica, porque el funcionamiento "automático" del mercado no resuelve la pobreza ni el desarrollo social. 
Contreras-Santos

Las posturas sobre las conexiones esbozadas entre el desarrollo y el Trabajo Social son negativas, cognitivas, afectivas y proactivas (2) en la dimensión metodológica, a raíz de que los conflictos y las violencias como determinantes en la estructuración de los territorios y del desarrollo regional y local no concuerdan con la aplicación de metodologías funcionales; existe crisis profesional, pues el trabajador social expone un perfil bajo en la esfera pública y privada, pese a sus fortalezas para liderar el desarrollo social.

Ciertamente, las actitudes de Trabajo Social ante el desarrollo impuesto en la región son poliformes. Especialmente, por sus desfavorables resultados, efectos e impactos en vastos grupos de la sociedad y la naturaleza. No obstante, el ideario del desarrollo aún se mantiene con posibilidades de modificación en nuestra (in)disciplinaprofesión. Esto que, a simple vista, podría resultar paradójico, revela la coexistencia de posturas contradictorias sobre ciertos atributos del desarrollo factibles de cambiar y disposiciones positivas relativas al sostén del desarrollo como megameta en sí, por incontables razones que ameritan inéditas pesquisas.

Puestas así las cosas, es clave suscitar reflexiones internas en todos los subcampos del Trabajo Social atinentes a sus actitudes frente al desarrollo, que escruten sus componentes (conocimientos, pensamientos, ideas, creencias, percepciones, sentimientos, conductas), funciones $u$ operaciones (utilitarias, cognitivas, protectoras, predictivas, ejecutantes, transformadoras), dimensiones, variables e indicadores (físicos, cognitivos, mentales, afectivos, espirituales), y clasificaciones (valoración, disposición, etc.).

\subsection{Las prácticas del desarrollo en el Trabajo Social}

En el corpus documental se precisan las prácticas del Trabajo Social en materia del desarrollo 183 veces, por cuanto se demarcan sus tiempos, escalas, actores, procesos, instrumentos, normas, documentos y entidades, justo como se dilucida en las siguientes partes (Figura 4). 
Figura 4. Las prácticas del desarrollo en el Trabajo Social

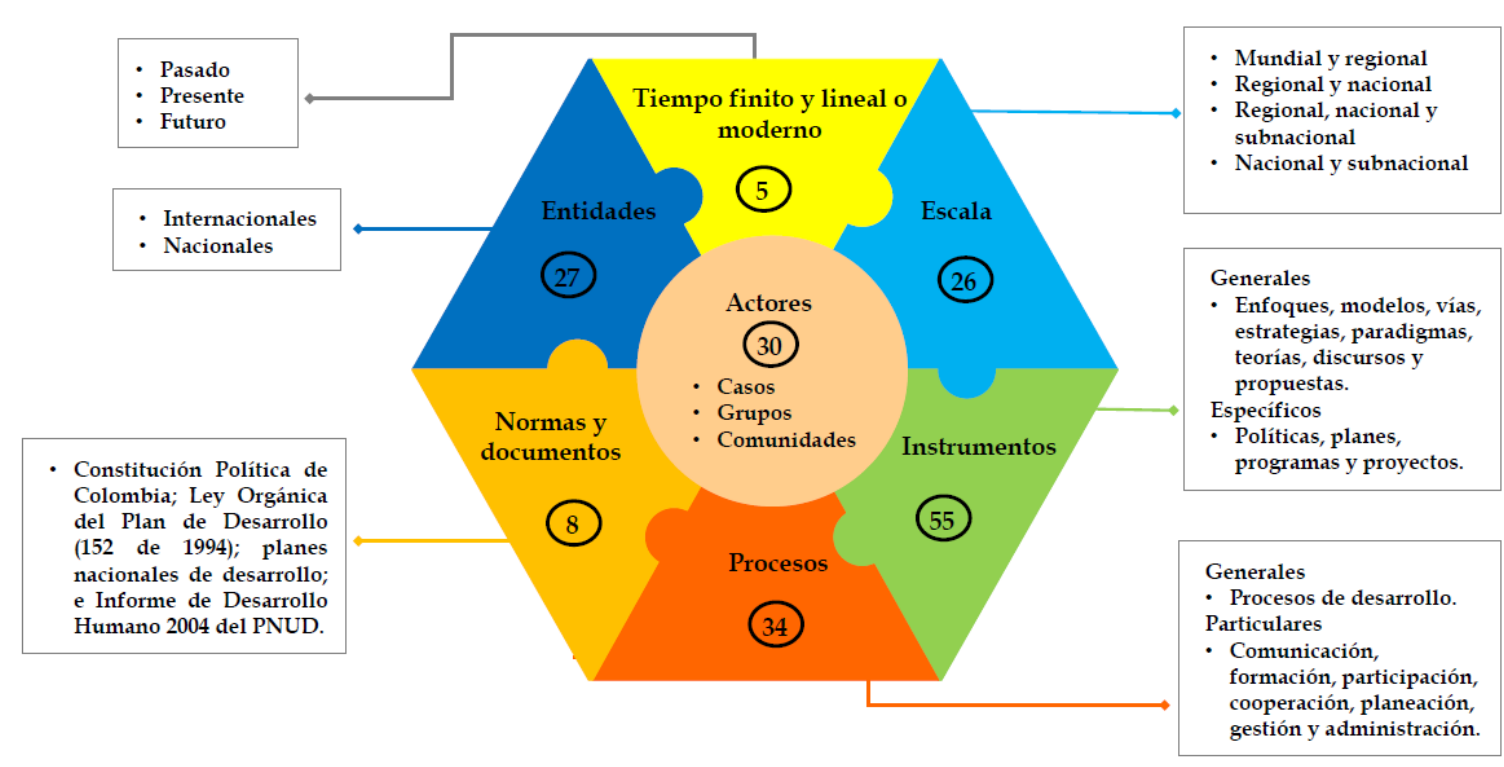

Fuente: elaboración propia.

Con respecto al tiempo, se indican lapsos finitos y lineales o periodos modernos (5): (i) pasado, 20 años atrás (década de 1970) se pensó que las naciones del "tercer mundo" eran un potencial de desarrollo y conflicto apto para valer sus fuerzas en el contexto internacional; (ii) presente y futuro, el ecodesarrollo y el desarrollo sostenible tienen por premisa la idea de que atender las necesidades del presente no debe comprometer las del futuro; y (iii) futuro, el desarrollo social es un proceso lento que demanda planes y programas coherentes de largo plazo.

Con respecto a la escala, se combinan las proporciones contemporáneas usuales (24): (i) mundial y regional (mundo con Latinoamérica y el Caribe; norte y sur; este y oeste; contextos mundial y continental; mundo bipolar, unipolar y multipolar; países no alineados; centro-periferia); (ii) regional y nacional (Europa-Norteamérica-Colombia; Latinoamérica y Colombia); (iii) regional, nacional y subnacional (Latinoamérica, Colombia, Medellín; América Latina-zonas urbanas y suburbanas; Latinoamérica y Cali, Bogotá, Medellín y su área metropolitana); (iv) nacional y subnacional (Colombia; Colombia y Orinoquía y Amazonía; Colombia y Chocó, Sucre, Nariño y Cauca; Cartagena).

Con respecto a los actores, se nombran empleando las categorías públicas y privadas vigentes (30): (i) casos (ser humano, persona, individuo, hombre, capacidades); (ii) grupos (personal, sectores pobres, trabajadores sociales, estudiantes; jóvenes, 
Contreras-Santos

organizaciones sociales, consejos); y (iii) comunidades (población, todos los sectores sociales, ciudadanía).

Con respecto a los procesos, se ingresan las secuencias convencionales de las dinámicas grupales y comunitarias (34): (i) totales (procesos de desarrollo) y (ii) parciales (comunicación, formación, participación, cooperación, planeación, gestión y administración).

Con respecto a los instrumentos, se registran los dispositivos típicos de la planeación del desarrollo (55): (i) genéricos, (enfoques, modelos, vías, estrategias, paradigmas, teorías, discursos y propuestas); y (ii) específicos, (políticas, planes, programas y proyectos).

Con respecto a las normas y a los documentos, se recurre a las reglas oficiales promulgadas (8): Constitución Política de Colombia; Ley Orgánica del Plan de Desarrollo (152 de 1994), y planes nacionales de desarrollo; Informe de Desarrollo Humano 2004 del PNUD.

Con respecto a las entidades, se compaginan firmas en funcionamiento (27): (i) internacionales (organismos, agencias de cooperación, Cepal, Unicef, Ilpes, OIT, PMA, PNUD) y (ii) nacionales (DNP, Contraloría General de la República, DANE, empresas, agentes financieros, organizaciones no gubernamentales, iglesias sindicatos, universidades, asociaciones profesionales, CONETS).

Tal como se abrevió en el primer apartado de este artículo, la trayectoria del Trabajo Social latinoamericano ocurre en el marco del desarrollo capitalista que, paralelamente, ha sido colonial y patriarcal. Por este irrebatible suceso, es improbable que las prácticas (in)disciplinares y profesionales escapen a sus influjos. Ante dicho cerco, el Trabajo Social ha reaccionado con diferentes pautas, desde su configuración hasta la fecha. Por ejemplo con: (i) su omisión al tratar casos, grupos y comunidades sin suficientes análisis contextuales o pocos estudios de sus tiempos, espacios, actores y eventos circunscritos en aquel desarrollo; (ii) su inclusión al juzgar que las materializaciones de sus referentes son oportunidades para su profesionalización; y (iii) su recusación al exigir su reconceptualización enmarcada en su transformación.

No obstante, pese a o dadas las (des)ventajas conseguidas en estas creaciones del asunto durante décadas, se visualiza insuficiente investigación a propósito de sus acervos de suerte que se complica disponer de acumulados reciclables como puntos de partida en las acciones de docencia, investigación y extensión del Trabajo Social que se 
Contreras-Santos

impulsan hogaño. Lo que se tiende a localizar es una exuberante diseminación de saberes y prácticas atravesadas -expresa o tácitamente- por el desarrollo moderno que, sea como fuere, en nuestros términos, demanda seguimiento, evaluación y sistematización de sistematizaciones, cuando menos.

\subsection{Las perspectivas del Trabajo Social en cuanto al desarrollo}

En el corpus documental se introducen 62 perspectivas del Trabajo Social sobre el desarrollo en forma de proposiciones, retos, interrogantes y supuestos (Figura 5).

Figura 5. Las perspectivas del Trabajo Social en cuanto al desarrollo.

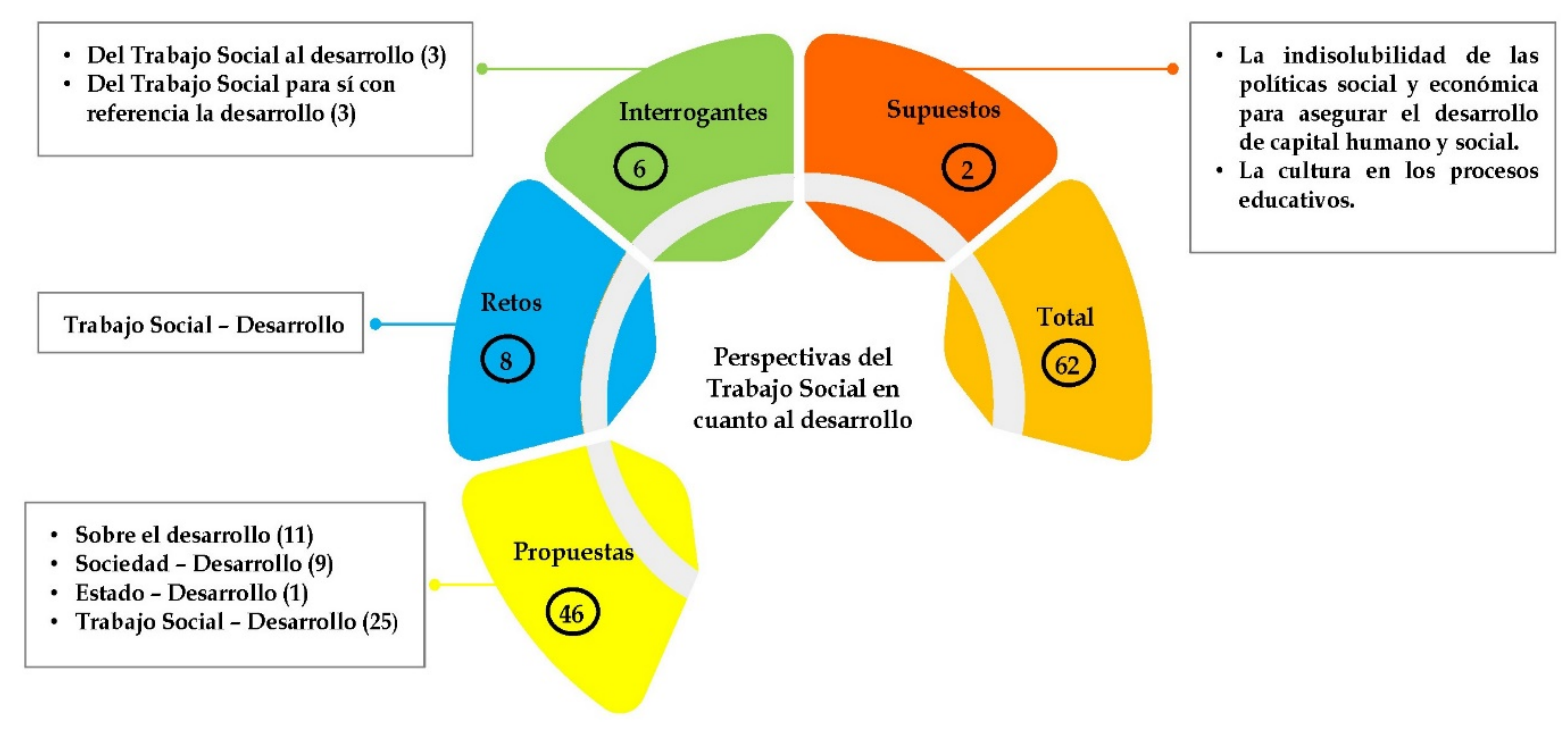

Fuente: elaboración propia.

\section{Las proposiciones del Trabajo Social en torno al desarrollo}

Las 46 proposiciones halladas denotan sustancias epistemológicas, ontológicas, contextuales, teóricas, metodológicas e instrumentales del Trabajo Social alusivas al desarrollo y de este con la sociedad, el Estado y el Trabajo Social, como se relaciona en la figura 5.

Las propuestas alrededor del desarrollo (11), refieren: (i) en función contextual, a saldar parte de la deuda del desarrollo agrario, dando respuesta no represiva a los cultivos ilícitos [sic] que es, en buena medida, desactivar una parte sustancial del conflicto armado colombiano; (ii) en función ético-política a: construir desarrollo 
Contreras-Santos

alternativo con estrategias articuladas de transformación social; perseguir la participación social como medio, objetivo y producto del desarrollo social; contener en el desarrollo social la organización, la solidaridad, el esfuerzo activo grupal y el comunitario, así como el profundo ethos solidario expresado en solidaridad interna de los pueblos, solidaridad internacional y solidaridad intergeneracional; enriquecer el desarrollo social con intercambio de experiencias entre las organizaciones populares y entre las instituciones y los organismos que les apoyan; (iii) en función teórica a: reconceptualizar la noción de "desarrollo"; asumir el carácter universal, holístico, integral de esta noción con una aproximación capaz de fomentar la sinergia en los procesos del desarrollo; cambiar la percepción y la ideación del desarrollo; defender el desarrollo regional y local como posibilidad de superación de las desigualdades; y (iv) en función instrumental a constituir un Fondo Mundial para el Desarrollo Social y el Combate de la Pobreza que incremente sus recursos financieros.

Las propuestas alrededor de las convergencias sociedad-desarrollo (9), apuestan: (i) en función contextual por una nueva lógica que articule personas, organizaciones, naturaleza, racionalidades económicas e iniciativas en procesos transformadores con superación de la pobreza, desarrollo social, protagonismo de los sectores populares empobrecidos y liberación del camino de la barbarie; y (ii) en función metodológica por la vinculación de la educación popular y el desarrollo social de modo que sus efectos se extiendan a la comunidad local.

La propuesta alrededor de la concurrencia Estado-desarrollo (1) sugiere, en función ético-política, pasar toda reforma política por una reconceptualización de lo social, que, partiendo de un análisis crítico del papel de los involucrados en la definición de la política social, redefina modelos de Estado, desarrollo económico y social, política social, planeación y participación ciudadana acordes con la realidad colombiana.

Las propuestas alrededor de las conjunciones trabajo social-desarrollo (25) evidencian: (i) en función epistemológica: ubicación crítica de sus paradigmas y concepción o adopción de paradigmas nuevos que permitan comprender la compleja existencia y construir caminos para el desarrollo latinoamericano con sentido teóricopráctico junto a otras disciplinas/profesiones; (ii) en función ético-política: asunción de compromiso ético-social que admita construir desarrollo con nuevos valores; ser y conocer; verdad y honestidad; equidad social y respeto a la heterogeneidad; respeto a derechos, deberes y reglas socialmente aceptadas; respeto a la vida y a su entorno; justicia; sostenibilidad; autonomía, gestión y lectura territorial; perspectiva de género; participación diversa de los actores; análisis comprensivo, crítico y propositivo de la realidad; expectativa de cambio estructural; (iii) en función ontológica: develamiento de 
Contreras-Santos

la identidad del trabajador social por el desarrollo humano integral; intervención decisiva para la formación integral y el afianzamiento innovador y propositivo de los jóvenes enfocados a erigir mejor ciudad, sociedad y territorio; (iv) en función teórica: investigación del desarrollo social; lectura científica del contexto, explicación de su dinámica e instrumentalización para su transformación; y (v) en función metodológica: gestación de condiciones para el desarrollo humano sostenible; elaboración de proyectos de desarrollo alternativo; innovación del caudal metodológico inspirado en un pensamiento social crítico y propositivo para el desarrollo regional y local.

Como se nota, las proposiciones son plurales, pero tienden al sostenimiento del desarrollo moderno. De hecho, expresan las preocupaciones perennes del Trabajo Social por resolver los problemas sociales que identifica en todos los escenarios. En prospectiva, más que reanimar polémicas acerca de sus afianzamientos, se recomienda intensificar las (de-re)construcciones de dicho desarrollo como ideario concebido por unos actores con unos postulados distantes de los lineamientos sociales y naturales que aseguró fortalecer.

Estos ejercicios deben aportar para ecocrear las urdimbres del desarrollo en el Trabajo Social con: incertidumbres, diálogos y decisiones de sus referentes epistemológicos, ético-políticos, ontológicos, contextuales, teóricos, metodológicos e instrumentales; adopciones, reformulaciones $y$ abandonos de sus conceptos; adaptaciones y (des-re)agregaciones de sus dimensiones, variables e indicadores; traducciones, confluencias, transversalidades y concreciones de sus componentes. Es decir, tales exámenes deben promover las reconstituciones de tramas comunes, abiertas y potentes que recopilen, concatenen y desborden los elementos analizados en trabajos como este.

\section{Los retos del Trabajo Social frente al desarrollo}

En el corpus documental se registran 8 desafíos del Trabajo Social contemplando el desarrollo y los contextos en los cuales se ubica (figura 5). Es decir, ante la problemática latinoamericana y colombiana, el Trabajo Social enuncia retos al desarrollo: adopción del desarrollo social como categoría teórica y como opción política que fundamente y plasme la estrategia de enfrentamiento de las desigualdades sociales contemporáneas; contribución a la construcción de una sociedad sostenible y equitativa con inserción mundial en situaciones de competitividad y desarrollo; encadenamiento de la sociedad del conocimiento con la construcción del desarrollo humano socialmente sustentable; lectura cuidadosa para caracterizar tendencias y oportunidades examinando los nuevos enfoques de desarrollo; interpelación, transformación y 
Contreras-Santos

fortalecimiento; resignificación con desplazamientos de los esquemas mentales de conocimiento, relaciones y análisis de los fenómenos sociales; comprensión profunda de los cambios a introducir en la profesión como base para apalancar el desarrollo social; cambio en las unidades académicas e, igualmente, renovación de organismos como el CONETS con análisis para responder al desarrollo local y regional.

Los retos expuestos son más coyunturales que estructurales, ya que su concentración es mayor en los cambios circunstanciales para mantener el desarrollo que en los cambios para prescindir de este como megameta occidental. Consecuentemente, es vital que el Trabajo Social produzca, circule y aplique conocimientos orgánicos de los cimientos, las bases o los fundamentos occidentales -con acentos latinoamericanos y colombianos- en los cuales el desarrollo surge, transmuta y se sostiene. Sin estas recapitulaciones es muy difícil superar múltiples problemas identificados en el corpus documental de este análisis, ya que, implícita o explícitamente, están enlazados al desarrollo moderno. Por ejemplo, para variadas voces, la injusticia, la iniquidad, la violencia, la pobreza y el ecocidio son perversiones que nacen, crecen y se sostienen con la expansión de la Modernidad, en cuyo sistema capitalista se ancla el desarrollo. Siendo así, ¿es viable resolver dichos malestares con la incorporación de adjetivos al desarrollo?

\section{Los interrogantes del Trabajo Social al desarrollo}

En el corpus documental se inscriben interrogantes peculiares de Trabajo Social al desarrollo 6 veces (figura 5). Los interrogantes del Trabajo Social al desarrollo (3) son: ¿desarrollo, para qué y para quiénes? ¿Es posible seguir pensando en el "desarrollo" de aquella forma [ideología del progreso: progresión ascendente de la humanidad hacia estados superiores]? ¿No será necesario pensarlo de manera distinta? ¿Cuál es la posibilidad de que el desarrollo local conviva con la permeabilidad y las tendencias inmanentes a la mundialización del capital y a la paradoja entre necesidades globales/locales? ¿Puede una comunidad de pequeños productores de manufacturas industria de confecciones o agricultura familiar- carear la gran empresa agrícola y minera o los megaproyectos ampliados con inversiones extranjeras?

Los interrogantes del Trabajo Social para sí, atinentes al desarrollo (3), son: ¿cómo interrelacionar profesiones en el desarrollo social con apropiación de campos del Trabajo Social? ¿Las universidades y los programas de Trabajo Social están preparando a sus profesionales para la intervención en la política pública y la formación política de sujetos y comunidades? ¿En esos estudios hacen formación con comunidades y están realmente preparados para planear el desarrollo local y regional? ¿Cuáles son los papeles de las ciencias sociales y del Trabajo Social en la comprensión y la intervención 
Contreras-Santos

de fenómenos asociados a migraciones, refugios, conflictos, violencias y desplazamientos forzados de actores, con énfasis en las perspectivas de género y generacional, los efectos en las dinámicas familiares y comunitarias, los procesos de intervención en el marco de la política pública, a escalas regional, nacional e internacional y sus implicaciones en el desarrollo regional y local?

Las preguntas inscritas, en cuestión de investigación, son más exploratorias, descriptivas, de encuadres y de asesorías que definitorias, clasificatorias, comparativas, de inferencias, predictivas, explicativas o evaluativas del desarrollo. Entonces, le corresponde al Trabajo Social elaborar sus propios y situados árboles de preguntas inherentes a sus lazos con el desarrollo, encaminados a robustecer su comprensión de las causas -directas, indirectas, estructurales- y las consecuencias -resultados, efectos e impactos- de esos nudos con la intención de resituar, reclasificar, reformular, rebatir o replicar las interpelaciones que se forja desde su aparición, además de obtener respuestas que le faciliten potenciar las investigaciones y las intervenciones que adelanta.

\section{Los supuestos del Trabajo Social referidos al desarrollo}

En el corpus documental se formulan dos supuestos del Trabajo Social ante el desarrollo. Estos se refieren a: (i) la indisolubilidad de las políticas social y económica para asegurar el desarrollo de capital humano y social, siendo este indispensable en el progreso de los pueblos; y (ii) la cultura en los procesos educativos, con pretensión de transformación del sujeto y las condiciones en que vive, implica pensarla, con método similar al del desarrollo, en los marcos de la Modernidad.

Los supuestos expresos en el corpus documental son escasos. Sin embargo, son una señal que consiente vislumbrar las oscilaciones del Trabajo Social frente al desarrollo. Asimismo, son una impronta que posibilita estudiar -por ejemplo, en materia de marco lógico- los acontecimientos, las restricciones o las decisiones necesarias, pero no controlables para el logro de esta megameta en los contextos donde el Trabajo Social adelanta sus labores.

\section{Conclusiones}

Dada la inmanencia y la trascendencia de las articulaciones del Trabajo Social con el desarrollo moderno, es necesario reavivar pesquisas de estas considerando incalculables referentes. En el presente artículo se resume la investigación documental desplegada para visibilizar rasgos del Trabajo Social alusivos al desarrollo despejados 
Contreras-Santos

por colegas, desde 1987, en los ejemplares de la Revista del CONETS reconociendo que esas conexiones se fraguan con el surgimiento de nuestra (in)disciplina-profesión y evolucionan con ella en permanente diacronía y sincronía.

La metodología del estudio permitió describir, analizar e interpretar conocimientos, actitudes, prácticas y perspectivas del Trabajo Social engranadas al desarrollo en los 12 artículos de la Revista cuyos títulos portan el término en cuestión.

En el corpus documental el desarrollo se usa 80 veces con significados (creación, crecimiento y desenvolvimiento), conceptos (referente, proceso) y atributos (sociales, ambientales, económicos, políticos y culturales) coexistentes en la vida cotidiana, los ámbitos científicos y el dominio del desarrollo moderno instalado en América Latina a partir de la segunda mitad del siglo XX.

A su vez, en ese corpus, se inscriben 32 posturas (negativas, cognitivas, racionales, afectivas, proactivas y reactivas) frente al desarrollo impuesto en Latinoamérica y Colombia, así como ante los enlaces de este con la sociedad, el Estado, el mercado y el Trabajo Social en sus dimensiones ontológicas, contextuales, teóricas, metodológicas e instrumentales, especialmente, por sus nefastos resultados, efectos e impactos en diversos grupos de la sociedad y la naturaleza.

También, en dicho corpus, se precisan las prácticas del Trabajo Social concernientes al desarrollo 183 veces, en la medida en que se puntualizan sus tiempos (lapsos finitos y lineales o periodos modernos); escalas (proporciones contemporáneas usuales); actores (mentados con las categorías públicas y privadas vigentes); procesos (series rutinarias de las dinámicas grupales/comunitarias); instrumentos (dispositivos típicos de la planeación del desarrollo); normas y documentos (reglas oficiales promulgadas); al igual que entidades (firmas en funcionamiento).

Adicionalmente, en aquel corpus, se introducen 62 perspectivas del Trabajo Social correspondientes al desarrollo, acuñadas como proposiciones (epistemológicas, ontológicas, contextuales, teóricas, metodológicas e instrumentales); retos (coyunturales); interrogantes (exploratorios, descriptivos, de encuadres y de asesorías); y supuestos (eventos no controlables) proclives a mantener el desarrollo como baluarte occidental más que a brindar aportes para su erradicación.

En general, el abordaje fortaleció los anhelos de constatar las complejas intersecciones sostenidas por el Trabajo Social con el desarrollo moderno en el mundo occidental desde su emergencia hasta la fecha. Por lo dicho o a su pesar, los ciclos de 
Contreras-Santos

conocimientos en torno a estas fusiones son desbordantes, pero reclaman seguimientos, evaluaciones y sistematizaciones. A lo mejor exhortan a elaborar estados del arte o estados de la cuestión compartidos. $\mathrm{O}$, aún más, requieren investigaciones colaborativas de segundo orden. Este tipo de pesquisa, de acuerdo con Molina y Del Castillo (2001, p. 28), es "una investigación que al observar su objeto obtiene también información sobre sí misma y es capaz de usar tal información para hacer más investigación, aumentando la potencia de la capacidad investigativa".

En cualquier caso, para solidificar sus avances, es ineludible que el Trabajo Social (re)implemente alternativas plurales encaminadas a (re)construir las especies de redes epistemológicas, ético-políticas, ontológicas, teóricas, metodológicas e instrumentales ligadas a la unidad de análisis que nos ocupa en incontables temporalidades y espacialidades.

Por ejemplo, analizar, las raíces y los desenvolvimientos de las primeras escuelas de Trabajo Social con entrecruzamientos del desarrollo moderno como megameta europea y americana contribuiría a clarificar para transformar estas remotas y recientes sujeciones. En este sentido, podríamos expandir los horizontes de los aprendizajes emanados de nuestra historia (in)disciplinar-profesional, tanto como lo ilustra Martínez:

La primera escuela [de Trabajo Social en Colombia] nos enseña a tener presente una visión integral de la humanidad, en contraposición con el conocimiento dividido y clasificado. Sobre todo, nos muestra un camino para trabajar frente a los conflictos sociales de una manera creativa y responsable, sin necesidad de definir enemigos, ni acudir al arrasamiento de las guerras. Si continuamos rescatando estas historias, es posible que algún día del siglo XXI, podamos continuar escribiendo las historias de las relaciones de baja entropía, de los vecindarios, del desarrollo comunitario, es decir, las historias hasta ahora inéditas de las paces. (Martínez, 2003, p. 10)

Ciertamente, debemos persistir para disponer de acumulados (re)utilizables como memorias colectivas vivas en (des-re)anclajes de las acciones impulsadas por el Trabajo Social colombiano actual. En este sentido, es inevitable: (i) acentuar los ciclos de (desre)conocimientos orgánicos acerca de los pilares occidentales modernos con los cuales se instaura el desarrollo en Latinoamérica y Colombia orientados a superar sus consustanciales problemas; (ii) potenciar los trabajos (in)disciplinares y profesionales analizando las disgregadas amalgamas del desarrollo moderno insertas en el Trabajo Social, así como en sus variados subcampos; (iii) seguir, evaluar y sistematizar los reforzamientos, los cambios o los relevos del desarrollo moderno (des-re)cubiertos por el Trabajo Social valorando sus resultados, efectos e impactos en la sociedad y en la 
Contreras-Santos

naturaleza; (iv) ecocrear las urdimbres del desarrollo en el Trabajo Social con (dere)construcciones relacionales propias; (v) elaborar árboles de preguntas atinentes a los lazos del Trabajo Social con el desarrollo que favorezcan sus relocalizaciones, reclasificaciones, refutaciones, reformulaciones o supresiones; (vi) incrementar las herramientas de producción, circulación y aplicación de conocimientos del Trabajo Social relativos al tema en escrutinio; y (vii) potenciar los medios de investigación e intervención en este y en todas las esferas dispuestas durante su transcurso por el CONETS - especialmente, la Revista- que, justamente, son surtidores idóneos de nuestras consolidación (in)disciplinar-profesional.

\section{Agradecimientos}

A la trabajadora social Mónica Lizeth Ruiz Osorio quien dio soporte en el procesamiento de los datos de este artículo.

A las trabajadoras sociales Zulma Cristina Santos Kerguelén y Gloria Montoya Cuervo y el trabajador social Jesús Glay Mejía Naranjo quienes aportaron ejemplares de la Revista.

A la trabajadora social Zulma Cristina Santos Kerguelén y los trabajadores sociales Jesús Glay Mejía Naranjo, Rafael Alberto Zambrano Vanegas y Juan Manuel Latorre Carvajal quienes ofrecieron información sobre la trayectoria del CONETS, con énfasis en el devenir de la Revista, y revisaron el manuscrito del artículo.

\section{Referencias bibliográficas}

Álvarez, J. R. (2009). Conclusiones del Congreso Nacional de Trabajo Social 2007. “Desarrollo local y regional, realidades y desafíos para el siglo XXI". Revista Colombiana de Trabajo Social, (21), 203-218.

Briceño-Ayala, R., y Ruiz-Guataquí Z. D. (2009). Colombia: política social y participación en los Planes Nacionales de Desarrollo 1998-2003. Revista Colombiana de Trabajo Social, (21), 33-51.

Consejo Nacional para la Educación en Trabajo Social [CONETS]. (2020). Misión y visión. Recuperado de https://conetsco.org/mision-y-vision/.

Contreras-Santos, M. (2006). Saber o hacer: ¿un falso dilema del Trabajo Social en Colombia? Trabajo Social, (8), 97-108. Recuperado de https://revistas.unal.edu.co/index.php/tsocial/article/view/8500/9144.

Contreras-Santos, M. (2010). Formación para la intervención en Trabajo Social. En C. Mosquera, M. J. Martínez y B. Lorente (Eds.), Intervención social, cultura y ética: un 
Contreras-Santos

debate interdisciplinario (pp. 435-465). Bogotá: Universidad Nacional de Colombia. Recuperado https://www.academia.edu/322787/Intervenci\%C3\%B3n_social_cultura_y_\%C 3\% A9ticaundebateinterdisciplinario.

Contreras-Santos, M. (2017). Trabajo Social y desarrollo. Notas de clase. Bogotá: Universidad Nacional de Colombia.

Cornely, S. A. (1994). Relatoría del Seminario Latinoamericano y Caribeño "Pobreza y Desarrollo". Revista Colombiana de Trabajo Social, (7), 95-104.

Departamento Nacional de Planeación (DNP). (2014). DNP definió seis categorías de ciudades colombianas de acuerdo a la edad de sus habitantes. Recuperado de https://www.dnp.gov.co/Paginas/DNP-defini\%C3\%B3-seis-

categor\%C3\%ADas-de-ciudades-colombianas-de-acuerdo-a-la-edad-de-sushabitantes.aspx.

Elizalde-Hevia, A. J. (1995). Visión y Prospectiva del Desarrollo Social a Escala Mundial. Revista Colombiana de Trabajo Social, (8), 17-46.

Gaitán-Quijano, B. (1992). La planeación estratégica y el desarrollo de personal de las empresas. Revista Colombiana de Trabajo Social, (5), 31-40.

Gómez-Hernández, E. (2009). Educación para el desarrollo en procesos de planeación participativa. Revista Colombiana de Trabajo Social, (21), 53-70.

López-Jiménez, C. I. (1999). Trabajo Social, identidad y desarrollo. Revista Colombiana de Trabajo Social, (13), 25-44.

Martínez, M. E. (2003). Presentación. En M. Cifuentes y L. Gartner, María Carulla de Vergara: entre la tradición y el progreso. Colombia: Universidad de Caldas.

Martínez, M. E., López, M., Saboyá, M., Rojas, H., y Poveda A. (1981). Historia del Trabajo Social en Colombia, 1900-1975. Bogotá: Tecnilibros.

Mejía-Naranjo, J. (2014). La organización gremial del Trabajo Social en Colombia, 1976-2012. Prospectiva. Revista de Trabajo Social e intervención social, (19), 441-459. doi: $10.25100 /$ prts.v0i19.981.

Mejía-Naranjo, J. (2003). Apuntes para una historia del CONETS. Recuperado de https://conetsco.org/historia/.

Molina, S., y Castillo, V. del. (2001). La investigación de segundo orden en ciencias sociales y su potencial predictivo: el caso del proyecto de Identidad y tolerancia. Revista Mexicana de Ciencias Politicas y Sociales, 44(182-3), 17-46. doi: 10.22201/fcpys.2448492xe.2001.182-3.48344.

Mota, A. E. (2009). Dinámicas sociales y gestión del desarrollo. Revista Colombiana de Trabajo Social, (21), 23-32.

Santos de Santos, Z. (2016). Trabajo Social Organizacional. Bogotá: Universidad Nacional de Colombia. 
Contreras-Santos

Torres-Sánchez, C. A. (1998). Desarrollo humano en la organización -Una visión sistémica-. Revista Colombiana de Trabajo Social, (12), 141-154.

Vargas de Roa, R. M. (1999). La formación académica del Trabajador Social Colombiano. Su papel en la transformación y desarrollo del país. Revista Colombiana de Trabajo Social, (13), 121-144.

Vargas de Roa, R. M. (2009). La formación en Trabajo Social para el desarrollo local y regional. Revista Colombiana de Trabajo Social, (21), 121-144.

Vargas-Velásquez, A. (2000). Colombia al comienzo del nuevo siglo: paz, desarrollo y gobernabilidad. Revista Colombiana de Trabajo Social, (14), 55-74. 


\section{OTROS ARTÍCULOS DE PROSPECTIVA No. 32 DE 2021}

\section{EDITORIAL}

Compromisos, dilemas y desafíos del Trabajo Social con dimensión colectiva en tiempos de pandemia

Enrique Pastor-Seller

\section{ARTÍCULOS}

La narrativa biográfica como alternativa para la comprensión del Conflicto y la violencia en Colombia: una experiencia pedagógica universitaria

Sara Sofía Castaño-Barco y Claudia BermúdezPeña

Experiencias de transición a la vida adulta de jóvenes que migraron solos. Un estudio en Aragón (España) Daniel Jiménez-Franco; Raquel Berzosa-Callén y Chabier Gimeno-Monterde

Fundamentals of Education in Intervention with Young Offenders. A Critical Review of a 'Successful' Case in Andalucía, España

David Herrera-Pastor

Subjetividad juvenil: lecturas desde y para el Trabajo Social en Colombia

Daniela Joya-Valbuena

Participación politica de los jóvenes del Valle del Cauca, Colombia, en la toma de decisiones públicas

Luis Eduardo Gutiérrez-Rojas y Amanda Ramírez-Giraldo

Victimización y perpetración de violencia en pareja adolescente y redes de apoyo en Colombia. Análisis con perspectiva de género

Johanna Alexandra Reina-Barreto
Apoyo social percibido, autoestima y maternidad adolescente: entre el respeto y la intrusión. Estudio en Traiguén, Chile

Gloria Mora-Guerrero, Luisa Escárate-Colín, Carol Espinoza-Lerdón y Andrea Peña-Paredes

El desarrollo en el Trabajo Social de Colombia: un campo transversal, disperso y polivalente

Maira Judith Contreras-Santos

Análisis de la situación laboral de las alimentadoras en la caficultura de la zona central colombiana, a la luz de la teoría de Nancy Fraser

Pablo Andrés Arango-Giraldo

Prioridades de investigación en la Obra social de empleados públicos, Mendoza, Argentina. Un estudio Delphi sobre producción de conocimientos en la seguridad social

Cecilia Amalia Molina

Producción de conocimiento y toma de decisiones. Relaciones entre academia y política pública para las familias en Colombia

José Raúl-Ruíz y Sandro Leonardo MunévarVargas

El staff de prácticas profesionales en Trabajo Social: espacio de fomento del aprendizaje autodirigido. Un estudio de caso en la Universidad Católica Luis Amigó, Colombia

Cristian Eduardo Blanco-García

\section{ARTISTA INVITADO}

Margie Reinel-Aguilar Ao Cicadidae

Prospectiva

\section{PROSPECTIVA Revista de Trabajo Social e Intervención Social}

No. 32 • jul.-dic. 2021

e-ISSN: 2389-993X • Universidad del Valle 